\title{
Anti-Methicillin Resistant Staphylococcus aureus (MRSA) Activity of Pseudoalteromonas flavipulchra Isolated from Marine Waters of Batangas, Philippines
}

\author{
Arizaldo E. CASTRO ${ }^{1, *}$ and Cristina C. SALIBAY ${ }^{2}$ \\ ${ }^{1}$ Institute of Biology, College of Science, University of the Philippines Diliman, Philippines \\ ${ }^{2}$ Biological Sciences Department, College of Science and Computer Studies, \\ De La Salle University- Dasmariñas, Philippines
}

('Corresponding author's e-mail: arizaldoc@yahoo.com)

Received: 26 August 2018, Revised: 31 October 2018, Accepted: 30 November 2018

\begin{abstract}
The ocean boasts untapped novel producers of antibiotic substances in the form of unicellular organisms. One of the newest bioproducers of pharmacologically-significant substances studied for its potential against clinically-significant pathogens is the genus Pseudoalteromonas, a gammaproteobacterial group. This study is a preliminary report detailing the isolation of a Pseudoalteromonas flavipulchra species from Philippine marine waters. The isolate coded as PAM-003 was identified as $100 \%$ similar to $P$. flavipulchra strain NCIMB2033 through 16s $r R N A$ gene amplification and sequencing. PAM-003 was allowed to produce bioactives for 12 days. Afterwards, nonpolar products were isolated from the base medium through membrane filtration, organic solvent extraction and rotary evaporation. The crude solution of bioactives injected in sterile discs was used for disc-diffusion assay against Methicillin Resistant Staphylococcus aureus (MRSA). Results indicate that PAM-003 demonstrated visually-appreciable zones of inhibition with a mean value of $8 \mathrm{~mm}$. To further describe the antibacterial activity of the isolate, minimum inhibitory concentration (MIC) of the bacterial extract was determined through broth microdilution technique. Results indicate that PAM-003 demonstrated a MIC of $1000 \mu \mathrm{g} / \mathrm{mL}$ against MRSA. Additional investigation on the bioactivity of Philippine isolates from the genus Pseudoalteromonas isolated from highly diverse regions of the country is a considerable initiative for increasing the pipeline of new molecular entities for drug discovery.
\end{abstract}

Keywords: Pseudoalteromonas, Marine waters, Antibacterial activity, Philippines

\section{Introduction}

A growing interest exists in the exploration of unique and untapped natural sources of antimicrobial substances possessing novel mechanisms of counteracting evolving infectious agents [1]. Recently, the Department of Health $(\mathrm{DOH})$ in the Philippines declared a national health emergency due to the increasing drug resistance in infectious organisms and entities [2]. Thus, a possible pre-antibiotic era would certainly burden clinicians and people suffering from infectious diseases [3].

In response to the global health issue of increasing antimicrobial resistance, a bandwagon of studies focusing on the identification and purification of novel antibiotic substances emerged as a priority research area [4]. Key organisms of interest include actinobacteria [5], plants [6], endophytic fungi [7], and diverse marine organisms capable of producing chemically-unique and active secondary metabolites. From these new sources of antibiotics, marine organisms have promised a lot in the field of antibiotic discovery and development [8]. In fact, there are literature describing the preclinical pharmacology of 
http://wjst.wu.ac.th

marine products which can possibly combat emerging drug-resistant infectious agents. Marine bacteria are an example of organisms that can be potential sources of novel antimicrobials [8].

Pseudoalteromonas is a noteworthy genus of Gammaproteobacteria that is currently studied for its anti-infective properties [8,9]. They are non-spore forming, non-bioluminescent, and motile species with single polar flagellum [9]. When grown in solid agar, Pseudoalteromonad colonies may be pigmented or not [9]. Previous studies documented the occurrence of different Pseudoalteromonads in marine niches and their antibiotic potentials [10-14]. Pseudoalteromonas species have also been shown to manifest antibiofilm activity [10] and bactericidal activity to drug-resistant bacteria [13]. Active compounds such as brominated metabolites [11], tambjamines [12], and polyketides [8] are just few of the chemotherapeutic-significant products of the genus. As antagonistic marine bacteria, members of the group were found to be frequently associated with biotic and abiotic surfaces [8]. Many reports detail the isolation of species belonging to this genus in sources such as nudibranchs [11], seawater [15], algae [14], and corals [16].

Methicillin-resistant Staphylococcus aureus (MRSA) has been reported as a prevalent hospitalacquired and community-associated pathogen in Asia accounting for a huge infectious disease burden in the region. MRSA's incidence varies among countries and has been observed to change over time. In clinical settings, it has been reported that hospitals in Asia harbor multidrug-resistant MRSA with estimated proportions between 28 to $>70 \%$ [17]. From a recent multi-country surveillance program, the proportion of community-associated and hospital-acquired MRSA in the Philippines are found to be at 30.1 and $38.1 \%$, respectively [18].

The exploration of marine-derived compounds especially those produced by metabolicallycompetitive Pseudoalteromonads is a promising field in chemotherapeutic pharmacology. In the light of this deduction, this study tested the extract of an isolate identified as P. flavipulchra from the marine waters of Anilao, Batangas and determined its antibacterial activity to an important nosocomial pathogen, MRSA.

\section{Materials and methods}

\section{Sampling site}

The sampling site for the study was in Anilao, Batangas, in the southern part of Luzon island, the Philippines. Location coordinates $\left(13^{\circ} 43.04^{\prime} \mathrm{N}, 120^{\circ} 52.14^{\prime} \mathrm{E}\right)$ were read with a GPS device (Garmin, Olathe, USA). Marine surface water samples were stored in 250-mL Low Density Polyethylene (LDPE) bottles and collected in triplicate. All samples were placed in an ice chest and were transported to the laboratory for processing.

\section{Isolation and culture of Pseudoalteromonas species}

Pseudoalteromonas species were isolated from the water samples via spread plating of $0.1 \mathrm{~mL}$ sample. A sterilized transferpipette and L-rod were used to spread plate water samples onto Marine Agar (HiMedia, Secunderabad, India) plates. Inoculated plates were incubated at $31{ }^{\circ} \mathrm{C}$ for $48 \mathrm{~h}$. Putative pigmented Pseudoalteromonas colonies were picked and re-isolated for purification. In each pigmentation, one colony was purified and characterized in terms of colonial morphology and appearance. To prevent death from autotoxic proteins, colonies were suspended in sterile Artificial Seawater (HiMedia, Secunderabad, India) prior to the molecular identification of the isolates and screening of extracts for antibaterial activity.

\section{Molecular identification of Pseudoalteromonas species}

After a $24 \mathrm{~h}$ growth period, whole genomic DNA was extracted from Marine Broth (HiMedia, Secunderabad, India) cultures of putative Pseudoalteromonas isolates using GF-1 Bacterial DNA Extraction Kit ${ }^{\circledR}$ (Vivantis Technologies, Singapore) according to the manufacturer's instructions.

PCR amplification of $16 \mathrm{~s} r R N A$ gene and its subsequent sequencing was done to determine the identity of the Pseudoalteromonas species isolated. Polymerase chain reaction (PCR) was performed in a $50 \mu \mathrm{L}$ reaction mixture containing $25 \mu \mathrm{L}$ PCR mastermix (QIAGEN, Singapore), $5 \mu \mathrm{L}$ each of the 
http://wjst.wu.ac.th

forward and reverse primers $(10 \mathrm{mM}), 10 \mu \mathrm{L}$ of RNAse-free water (QIAGEN, Singapore), and $5 \mu \mathrm{L}$ of whole genomic DNA from isolates. Primer design were as follows: (fD1): 5'CCGAATTCGTCGACAACAGAGTTTGATCCTGGCTCAG, Reverse strand (rD1): CCCGGGATCCAAGCTTAAGGAGGTGATCCAGCC-3'. Amplification was performed in a pre-set thermocycler (G-Storm, Somerset, United Kingdom) under the following conditions: Initial Denaturation for $3 \mathrm{~min}$ at $94{ }^{\circ} \mathrm{C}$, Denaturation for $1 \mathrm{~min}$ at $94{ }^{\circ} \mathrm{C}$, Annealing for $1 \mathrm{~min}$ at $60{ }^{\circ} \mathrm{C}$ Extension for $1.5 \mathrm{~min}$ at $72{ }^{\circ} \mathrm{C}$, and Final Extension for $10 \mathrm{~min}$ at $72{ }^{\circ} \mathrm{C}$. Electrophoresis of the PCR product was done in $1.5 \%$ agarose gel for $45 \mathrm{~min}$ at $110 \mathrm{mv}$ (Bio-Rad Laboratories, California, USA). Amplicons were shipped for purification and sequencing to 1st BASE Malaysia via Asiagel Corporation. Editing of the sequences was done with BioEdit Sequence Alignment Editor (Ibis Therapeutics, Carlsbad, USA). The obtained sequences were compared to sequences available in GenBank ${ }^{\circledR}$ using the BLAST search to facilitate species identification [16]. A $97 \%$ sequence similarity was used as threshold for identifying each isolate.

\section{Screening of extracts for antibacterial activity}

Identified Pseudoalteromonas isolates were sub-cultured in $300 \mathrm{~mL}$ Marine Broth for $48 \mathrm{~h}$ at $31^{\circ} \mathrm{C}$. Twenty (20) $\mathrm{mL}$ of the sub-culture was transferred afterwards to a $1,000 \mathrm{~mL}$ marine broth and was grown without agitation for 12 days. Cell-free supernate was separated from pellet via centrifugation at 8,000 $x \mathrm{~g}$ for $5 \mathrm{~min}$. Supernatant underwent further vacuum filtration using a $0.2 \mu \mathrm{m}$ filter to ensure that it was free of bacterial cells. Cell-free supernatants were partitioned with same volume of ethyl acetate (Univar, Downers Grove, USA) and was afterwards concentrated using a rotary evaporator (Heidolph Instruments, Schwabach, Germany) at a temperature of $60{ }^{\circ} \mathrm{C}$ resulting to thickened extract that is free from of the ethyl acetate solvent.

Using the disc-diffusion method, the antibacterial activities of the extracts to Methicillin-resistant Staphylococcus aureus (MRSA) were evaluated in triplicate. $20 \mu 1$ of each extract were charged to sterile 6-mm filter papers. Sterilized filter papers were also used for the negative control (Ethyl Acetate) and positive controls which are Gentamicin and Chloramphenicol (MAST Group Ltd., Bootle Merseyside, UK). Mueller Hinton Agar (HiMedia, Secunderabad, India) was used as the solid medium for the discdiffusion assay. Plates were then incubated at $37^{\circ} \mathrm{C}$ for $18 \mathrm{~h}$. Zones of inhibition (ZOI) were measured in millimeter using a vernier caliper (Mitutoyo Corporation, Kanagawa, Japan) after the indicated incubation period.

Determination of minimum inhibitory concentration values using Broth microdilution method

Broth microdilution was done to determine the minimum inhibitory concentrations of each bacterial crude extracts. MRSA (Accession number: BIOTECH10378) was requested from the Philippine National Collection of Microorganisms and was grown in Mueller Hinton Broth for $18 \mathrm{~h}$ at $37{ }^{\circ} \mathrm{C}$. The extracts were prepared in the following amounts: 1,000, 500, 250, 125, 62.5, 31.25, 15.63 and $7.81 \mu \mathrm{g} / \mathrm{mL}$. All were tested against $50 \mu \mathrm{L}$ of bacterial cell suspension. Positive controls, Gentamicin and Chloramphenicol (MAST Group Ltd., Bootle Merseyside, UK) and negative control were also tested against the bacterial pathogen. Plates were incubated for $20 \mathrm{~h}$ at $37^{\circ} \mathrm{C}$.

\section{Data collection}

The identities of the Pseudoalteromonas isolates were ascertained using the results of colonial characteristics as well as the $16 \mathrm{~s} r R N A$ gene-PCR assay through comparison of DNA sequence data to

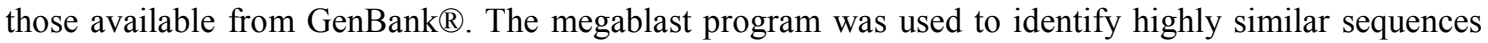
matching the sequence data from the isolates. Meanwhile, inhibition profiles against MRSA were indicated by the presence of a zone of inhibition (ZOI) recorded in millimeters around the impregnated discs containing the concentrated crude extracts of the isolates. The minimum inhibitory concentration values were determined by broth microdilution. MICs were interpreted according to CLSI guidelines in order to determine if the test pathogen can be inhibited by the crude extracts. 
http://wjst.wu.ac.th

\section{Results and discussion}

\section{Colonial characteristics of presumptive Pseudoalteromonads}

The isolates' morphological characteristics conform to the expected traits of known Pseudoalteromonas species and strains. All isolates appeared as circular, butyrous, and opaque colonies when purified in marine agar. The pigmentations of the isolates were also variable as indicated by the set of colors they sported after $24 \mathrm{~h}$ growth in solid medium. PAM-001 and PAM-002 were both colored orange. PAM-003 was colored lemon yellow [20] (Figure 1) while PAM-004 was colored pink. All 4 isolates were found as gram-negative cells.

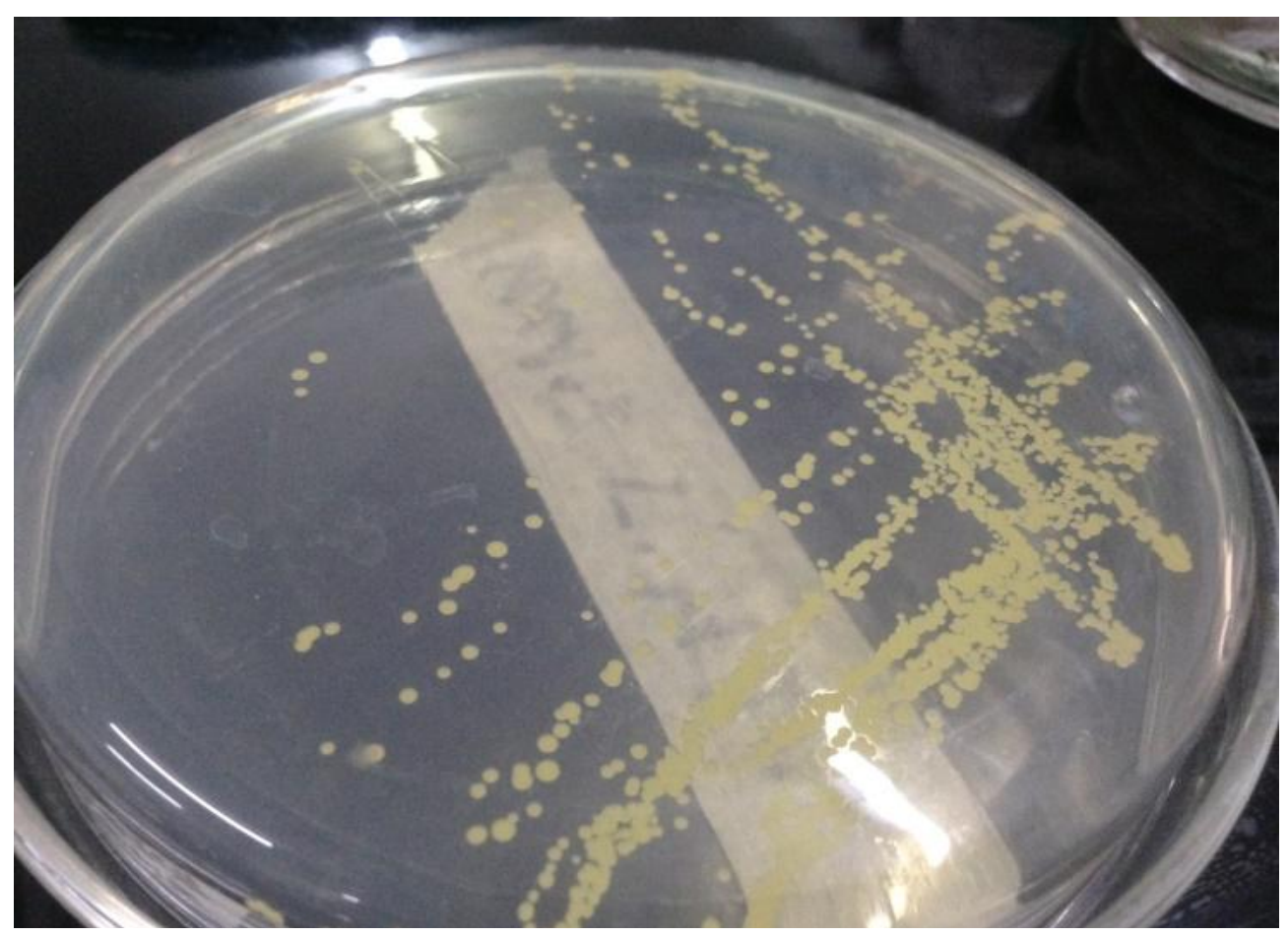

Figure 1 PAM-003 grown in Marine agar appearing as lemon yellow colonies. 


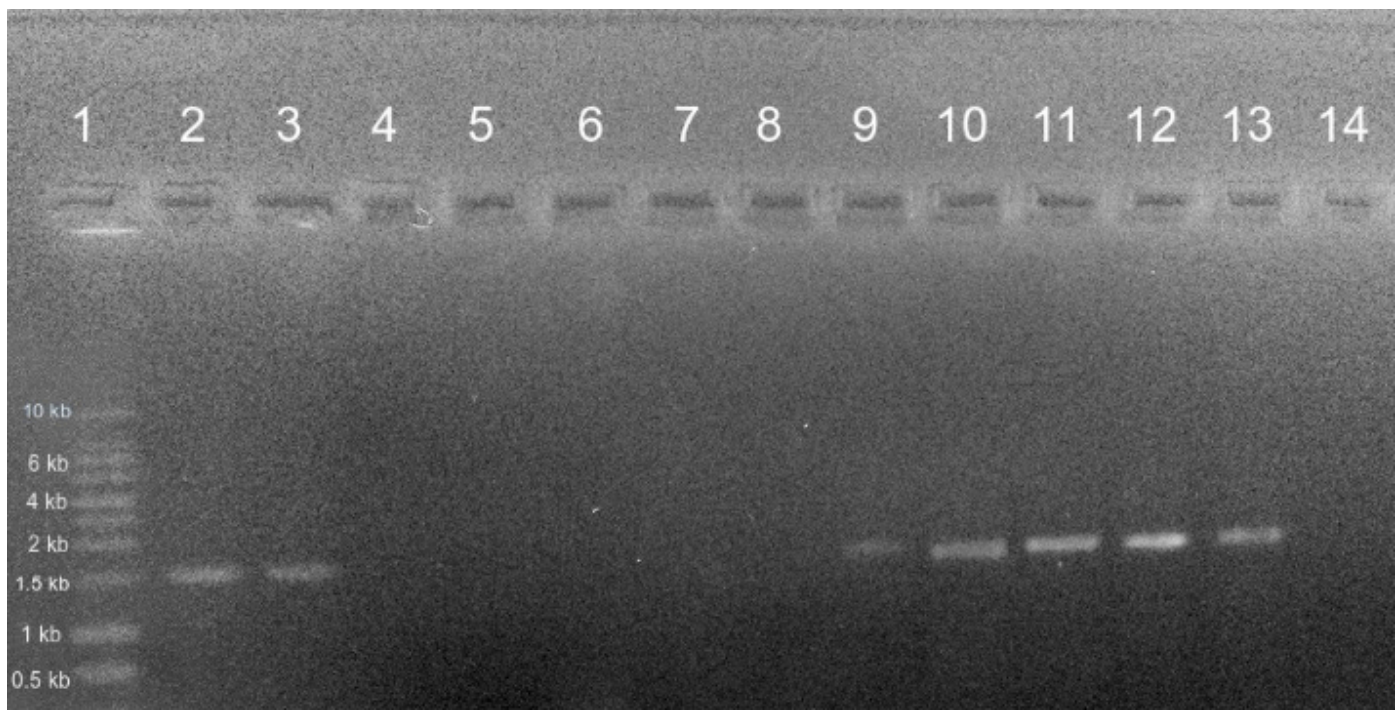

Figure 2 Gel electrophoresis of 16 s rRNA gene amplicons.

*Lane \# 1 - DNA Ladder; Lanes 2-8 and 13 - Non-Pseudoalteromonas isolates; Lane 9 - PAM-001;

Lane 10 - PAM-002; Lane 11-PAM-003; Lane 12-PAM-004; Lane 14 - Negative control

\section{Identities of Presumptive Pseudoalteromonads and PAM-003 as P. flavipulchra}

From the PCR assay, amplicons were expected to have a size of around $1.5 \mathrm{~kb}$ (Figure 2). Following a $97 \%$ sequence similarity threshold for determining the nature of the isolates, the identities of the 4 presumptive Pseudoalteromonads (Table 1) were finally ascertained as belonging to the taxonomic classification of the genus since all of them were found to have a $98 \%$ sequence similarity and above [18]. PAM-003 was closely related to Pseudoalteromonas flavipulchra strain NCIMB 2033 with $100 \%$ sequence similarity.

Table 1 Identities of Presumptive Pseudoalteromonas inferred from 16s rRNA gene PCR assay.

\begin{tabular}{ccc}
\hline Isolate Code & Related reference strain & \% similarity of sequences \\
\hline PAM-001 & Pseudoalteromonas piscicida & 99 \\
PAM-002 & NBRC 103038 & 98 \\
PAM-003 & Pseudoalteromonas piscicida & 100 \\
PAM-004 & Pseudoalteromonas \\
& flavipulchra NCIMB 2033 \\
Pseudoalteromonas phenolica & 98 \\
\hline
\end{tabular}

\section{Antibacterial activity of Pseudoalteromonas crude extracts}

From the four Pseudoalteromonad isolates, only the crude ethyl acetate extracts of PAM-003 manifested inhibitory activity against MRSA (Table 2). It produced a zone of inhibition with a mean diameter of $8.00 \mathrm{~mm}$ (Figure 3). 
http://wjst.wu.ac.th

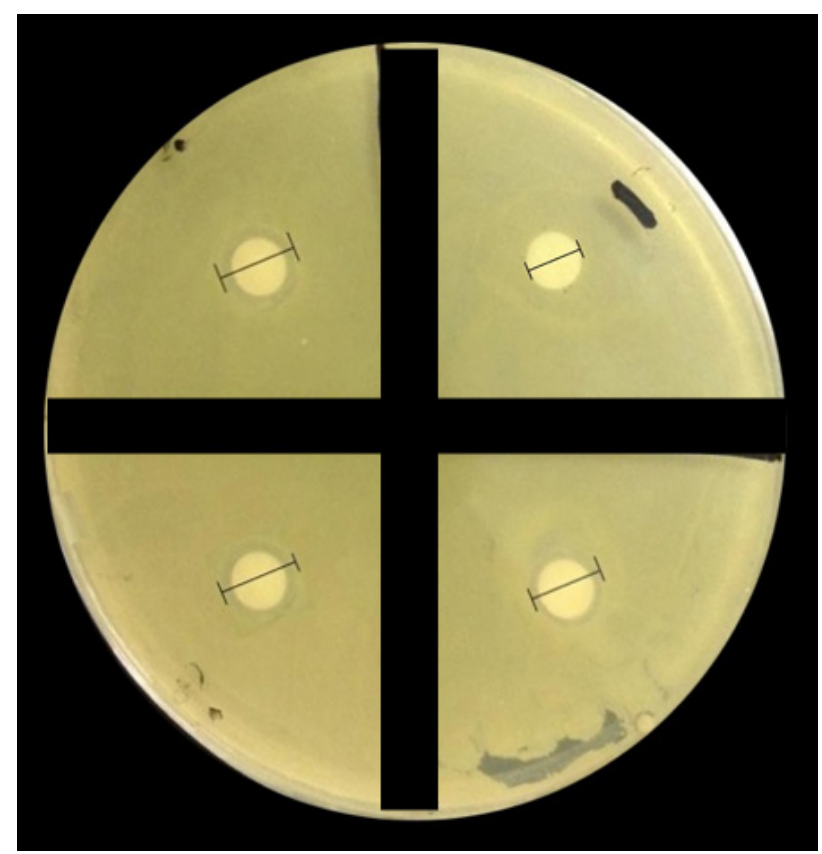

Figure 3 ZOIs manifested by crude extracts of PAM-003 (Q1, Q3, and Q4) against MRSA vs. Negative Control (Q2).

Table 2 Zones of Inhibitions (mm) produced by crude extracts of Pseudoalteromonas isolates and positive and negative controls against bacterial panel of pathogens.

\begin{tabular}{cccccccc}
\hline Pathogen & $\begin{array}{c}\text { PAM- } \\
\mathbf{0 0 1}\end{array}$ & $\begin{array}{c}\text { PAM- } \\
\mathbf{0 0 2}\end{array}$ & $\begin{array}{c}\text { PAM- } \\
\mathbf{0 0 3}\end{array}$ & $\begin{array}{c}\text { PAM- } \\
\mathbf{0 0 4}\end{array}$ & $\begin{array}{c}\text { Gent } \\
(+)\end{array}$ & $\begin{array}{c}\text { Chlor } \\
(+)\end{array}$ & $\begin{array}{c}\text { EA } \\
(-)\end{array}$ \\
\hline MRSA & 6.00 & 6.00 & 8.00 & 6.00 & 23.00 & 26.00 & 6.00
\end{tabular}

*Legend: PAM-00_-Pseudoalteromonas isolate, Gent-Gentamicin, Chlor-Chloramphenicol, EA - Ethyl acetate, G + Gram positive, G - - Gram negative, MRSA- Methicillin-resistant Staphylococcus aureus, $6.00 \mathrm{~mm}$ - diameter of the disk, no inhibition observed

\section{Minimum inhibitory concentration of PAM-003's extract}

The crude extract of PAM-003 inhibited the growth of MRSA at a concentration of $1,000 \mu \mathrm{g} / \mathrm{mL}$ (Table 3). This is numerically similar to the MIC of Chloramphenicol. However, it is important to note that according to CLSI guidelines, MRSA used in the assay is resistant to the commercial Chloramphenicol used as it manifested a MIC of greater than $32 \mu \mathrm{g} / \mathrm{mL}$ (prepared antibiotic was seen to inhibit MRSA growth only at the highest concentration of $1,000 \mu \mathrm{g} / \mathrm{mL}$ similar with PAM-003's extract). 
http://wjst.wu.ac.th

Table 3 MIC $(\mu \mathrm{g} / \mathrm{mL})$ produced by crude extracts of Pseudoalteromonas isolates and positive and negative controls against MRSA.

\begin{tabular}{|c|c|c|c|c|c|c|c|}
\hline Pathogen & $\begin{array}{c}\text { PAM- } \\
001\end{array}$ & $\begin{array}{c}\text { PAM- } \\
002\end{array}$ & $\begin{array}{c}\text { PAM- } \\
003\end{array}$ & $\begin{array}{c}\text { PAM- } \\
004\end{array}$ & $\begin{array}{c}\text { Gent } \\
(+)\end{array}$ & $\begin{array}{c}\text { Chlor } \\
(+)\end{array}$ & $\begin{array}{c}E A \\
(-)\end{array}$ \\
\hline MRSA & - & - & 1000 & - & 7.81 & 1000 & - \\
\hline
\end{tabular}

*Legend: PAM-00_Pseudoalteromonas isolate, Gent-Gentamicin, Chlor-Chloramphenicol, EA - Ethyl acetate, G + Gram positive, G - - Gram negative, MRSA- Methicillin-resistant Staphylococcus aureus

\section{Presence of pigmented Pseudoalteromonads in Philippine marine waters}

In the laboratory, Pseudoalteromonads are characterized to be true marine bacteria since they require a seawater base for growth [9]. Pseudoalteromonads have attracted significant interest from the scientific community due to their potential in the production of bioactives [8]. In aquatic environments, they are found associated with macroorganisms and surface water. Similar to other studies, Pseudoalteromonas isolates have been shown to exist in Asian marine waters such as in Indonesia [21]. This preliminary report of potentially bioactive Pseudoaltermonads in Philippine marine waters suggests the need to further exploit the pool. The presence of such pigmented Pseudoalteromonad species may be attributed to the high marine biodiversity levels of Philippine marine waters.

\section{Bioactivity of PAM-003}

One previously reported Pseudoalteromonad isolate in the Philippines was found to be algalytic inducing $100 \%$ mortality on Pyrodinium bahamense var. compressum (Bohm) Steidinger, Tester and Taylor [22]. Another study reported an isolate's enzymatic capacity to hydrolyze polysaccharides from seaweeds [23]. In the current study, PAM-003's bioactivity is manifested to be antibacterial to MRSA as indicated by the presence of a zone of inhibition around the discs containing the isolate's extracts. PAM003 is identified to be closely related to the P. flavipulchra isolate reported in $\mathrm{Yu}$ et al. [24]. The observed inhibition may be attributed to the presence of ethyl acetate soluble compounds in PAM-003's extract which are possibly similar to the products of $\mathrm{Yu}$ et al. P. flavipulchra isolate [24]. In a similar study by Feher and colleagues, brominated compounds were isolated from an unidentified Pseudoalteromonas species and had significant effect against MRSA [10]. Carboxylic acids, ketones, and deoxy-nucleosides are some of the molecules reported to be produced by bioactive Pseudoalteromonads. These molecules are known as low molecular weight substances that are mostly non-polar and may induce death of bacterial cells by virtue of the active functional group that the molecules possess.

The inhibitory activity of PAM-003 against MRSA can be further supported by a $1,000 \mu \mathrm{g} / \mathrm{mL}$ minimum inhibitory concentration. In an independent study from Indonesia, a similar isolate has been shown to have an effect against multi-drug resistant pathogens such as Acinetobacter baumanii and Enterobacter aerogenes [21]. Factoring in the manner of preparation of the potential antimicrobial substances of PAM-003 as crude extracts, inhibitory activity can be considered as existing and exploitable.

\section{Conclusions}

This study reports the anti-MRSA activity of PAM-003, identified as closely related to $P$. flavipulchra. PAM-003 exerted visually-appreciable zones of inhibition measuring a mean diameter of $8.00 \mathrm{~mm}$. In addition, this inhibitory activity is further supported by the results of the MIC assay. PAM003 was able to inhibit MRSA at a concentration of $1,000 \mu \mathrm{g} / \mathrm{mL}$.

As supported by the findings of this research, bioactive prokaryotes such as species under the genus Pseudoalteromonas are thriving in Philippine marine waters and they represent an unexploited pipeline of aquatic microbes that can be further studied for their antibiotic potentials. Further investigation on the bioactivity of Philippine Pseudoalteromonad isolates from other highly diverse regions of the country 
http://wjst.wu.ac.th

must be considered as a way forward for increasing the pipeline of new molecular entities for drug discovery.

\section{Acknowledgements}

The study was funded by the Commission on Higher Education (CHED) of the Republic of the Philippines through the CHED Thesis Grant Program.

\section{References}

[1] BS Seal, D Drider, BB Oakley, H Brüssow, D Bikard, JO Rich, S Miller, E Devillard, K Kwan, G Bertin, S Reeves, SM Swift, M Raicek and CG Gay. Microbial-derived products as potential new antimicrobials. Vet. Res. 2018; 49, 66.

[2] Department of Health. Available at: http://icamr.doh.gov.ph/index.php/8-featured-articles/18-dohlaunches-the-national-antibiotic-guidelines, accessed February 2017.

[3] M Asif, IA Alvi, SU Rehman. Insight into Acinetobacter baumannii: Pathogenesis, global resistance, mechanisms of resistance, treatment options, and alternative modalities. Infect. Drug. Resist. 2018; 11, 1249-60.

[4] LM Alcantara, TCS Ferreira, FR Gadelha and DC Miguel. Challenges in drug discovery targeting TriTryp diseases with an emphasis on leishmaniasis. Int. J. Parasitol. Drugs Drug Resist. 2018; 8, 430-9.

[5] S Velho-Pereira and NM Kamat. Antimicrobial screening of actinobacteria using a modified crossstreak method. Indian J. Pharm. Sci. 2011; 73, 223-8.

[6] ARM Coates, G Halls and Y Hu. Novel classes of antibiotics or more of the same? Br. J. Pharmacol. 2011; 163, 184-94.

[7] NAMN Hazalin, K Ramasamy, SM Lim, IA Wahab, ALJ Cole and ABA Majeed. Cytotoxic and antibacterial activities of endophytic fungi isolated from plants at the National Park, Pahang, Malaysia. BMC Complement Altern. Med. 2009; 9, 46.

[8] C Offret, F Desriac, PL Chevalier, J Mounier, C Jégou and Y Fleury. Spotlight on antimicrobial metabolites from the marine bacteria Pseudoalteromonas: Chemodiversity and ecological significance. Mar. Drug. 2016; 14, E129.

[9] JP Bowman and TAM Meekin. Pseudoalteromonas. Bergey's Manual of Systematics of Archaea and Bacteria. John Wiley \& Sons, 2015.

[10] A Dheilly, E Soum-Soutera, GL Klein, A Bazire, C Compere, D Haras and A Dufour. Antibiofilm activity of the marine bacterium Pseudoalteromonas sp. strain 3J6. Appl. Environ. Microbiol. 2010; 76, 3452-61.

[11] D Feher, R Barlow, JM Atee and TK Hemscheidt. Highly brominated antimicrobial metabolites from a marine Pseudoalteromonas sp. J. Nat. Prod. 2010; 73, 1963-6.

[12] A Franks, P Haywood, C Holmstrom, S Egan, S Kjelleberg and N Kumar. Isolation and structure elucidation of a novel yellow pigment from the marine bacterium Pseudoalteromonas tunicata. Molecules 2005; 10, 1286-91.

[13] A Isnansetyo and Y Kamei, MC21-A, a bactericidal antibiotic produced by a new marine bacterium, Pseudoalteromonas phenolica sp. Nov. O-BC30T, against Methicillin-resistant Staphylococcus aureus. Antimicrob. Agents Chemother. 2003; 47, 480-8.

[14] S Egan, C Holmstrom and S Kjelleberg. Pseudoalteromonas ulvae sp. nov., a bacterium with antifouling activities isolated from the surface of a marine alga. Int. J. Syst. Evol. Microbiol. 2001; 51, 1499-504.

[15] YS Oh, AR Park, JK Lee, CS Lim, JS Yoo and DH Roh. Pseudoalteromonas donghaensis sp. nov. isolated from seawater. Int. J. Syst. Evol. Microbiol. 2011; 61, 351-5.

[16] M Shnit-Orland and A Kushmaro. Coral mucus-associated bacteria: A possible first line of defense. FEMS Microbiol. Ecol. 2009; 67, 371-80. 
http://wjst.wu.ac.th

[17] CJ Chen and YC Huang. New epidemiology of staphylococcus aureus infection in Asia. Clin. Microbiol. Infect. 2014; 20, 605-23.

[18] JH Song, PR Hsueh, DR Chung, KS Ko, CI Kang, KR Peck, JS Yeom, SW Kim, HH Chang, YS Kim, SI Jung, JS Son, TM So, MK Lalitha, Y Yang, SG Huang, H Wang, Q Lu, CC Carlos, JA Perera, CH Chiu, JW Liu, A Chongthaleong, V Thamlikitkul and PH Van. Spread of methicillinresistant Staphylococcus aureus between the community and the hospitals in Asian countries: An ANSORP study. J. Antimicrob. Chemother. 2011; 66, 1061-9.

[19] NG Vynne and L Gram. 2011, Bioactivity and Phylogeny of the Marine Bacterial Genus Pseudoalteromonas. Ph.D. Dissertation. Technical University of Denmark, Denmark.

[20] EP Ivanova, T Sawabe, AM Lysenko, NM Gorshkova, VI Svetashev, DV Nicolau, N Yumoto, T Taguchi, S Yoshikawa, R Christen and VV Mikhailov. Pseudoalteromonas ruthenica sp. nov., isolated from marine invertebrates. Int. J. Syst. Evol. Microbiol. 2002; 52, 235-40.

[21] D Ayuningrum, R Kristiana, MA Asagabaldan, A Sabdono, OK Radjasa, H Nuryadi, A Trianto, Isolation, characterization and antagonistic activity of bacteria symbionts of hard coral Pavona sp. isolated from Panjang Island, Jepara against infectious multi-drug resistant (MDR) bacteria. IOP Conf. Ser. Earth Environ. Sci. 2017; 55, 012029

[22] RV Azanza, VMD Vargas, K Fukami, K Shashank, DFL Onda and MPV Azanza. Culturable algalytic bacteria isolated from seaweeds in the Philippines and Japan. J. Environ. Sci. Manag. $2013 ; 1,1-10$.

[23] BM Henares, EP Enriquez, FM Dayrit and NRL Rojas. Iota-carrageenan hydrolysis by Pseudoalteromonas carrageenovora IFO 12985. Philipp. J. Sci. 2010; 139, 131-8.

[24] M Yu, J Wang, K Tang, X Shi, WM Zhu and XH Zhang. Purification and characterization of antibacterial compounds of Pseudoalteromonas flavipulchra JG1. Microbiology 2012; 158, 835-42. 